\section{Acessibilidade no ambiente escolar: problemas e desafios baseados na observação de escolas em Santa Maria/RS}

\author{
Accessibility in the school environment: \\ problems and challenges based on the observation \\ of schools in Santa Maria/RS
}

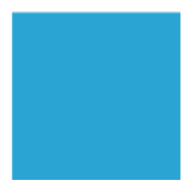

Revista

Extensão em Foco

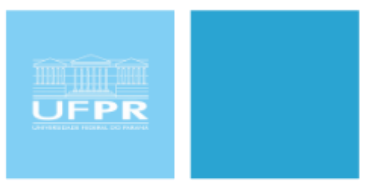

ISSN $2358-7180$

\author{
Aline Dalcul ${ }^{1}$, Marcia Berselli
}

RESUMO

\begin{abstract}
Com o intuito de mapear a situação da acessibilidade nas escolas públicas da cidade de Santa Maria, no Rio Grande do Sul, as autoras fazem um levantamento sobre a inclusão nesses espaços de ensinoaprendizagem. Vinte escolas da rede pública estadual e municipal da cidade foram visitadas, sendo verificados aspectos arquitetônicos, metodológicos e atitudinais. A partir de tal levantamento, o artigo apresenta uma reflexão sobre o papel da escola e os modos de compreensão da inclusão no campo da educação. Compreendendo a escola como um local em que as relações devem ser promovidas, destacase a importância do diálogo na solução e mediação de conflitos. A partir dos dados observados, o investimento na formação continuada de professores parece ser uma resposta importante às demandas relativas à inclusão, ampliando o conhecimento sobre questões relativas à deficiência.
\end{abstract}

Palavras-chave: Acessibilidade. Inclusão. Escola.

\title{
ABSTRACT
}

To map the accessibility situation in public schools in the city of Santa Maria, in Rio Grande do Sul, the authors realize a survey about inclusion in these teaching-learning spaces. Twenty state and municipal public schools of the city were visited, being verified architectural, methodological and attitudinal aspects. From this survey, the article presents a reflection on the role of the school and the ways of understanding inclusion in the education field. Understanding the school as a place where relations should be promoted, the importance of dialogue in the solution and mediation of conflicts is highlighted. From the data observed, the investment in continuing teacher education seems to be an important answer to the demands related to inclusion, expanding knowledge about issues related to disability.

Keywords: Accessibility. Inclusion. School.

\footnotetext{
${ }^{1}$ Graduada em Ciências Biológicas - Bacharelado e Licenciatura. Universidade Federal de Santa Maria (UFSM), Santa Maria, Rio Grande do Sul, Brasil. E-mail: alinepoescker@hotmail.com. Orcid: https://orcid.org/0000-0002-1781-5228

${ }^{2}$ Doutora em Artes Cênicas. Professora Adjunta. Universidade Federal de Santa Maria (UFSM), Santa Maria, Rio Grande do Sul, Brasil. E-mail: bersellimarcia@gmail.com. Orcid: https://orcid.org/0000-00022731-1373
} 
Pátio da escola. Duas e meia da tarde. Estou esperando. João caminha pelo pátio. Ouve uma voz: “João, não corre!”. Ele olha, para. Não tem o que fazer. Sobe para o segundo andar. Cadê o João?? Alguém viu o João? Acho que ele subiu, alguém diz. Mas esse menino... Vai buscar o João. João volta para o pátio. Anda pra lá, anda pra cá. Não conversa com ninguém. Ninguém conversa com ele. Está atento a tudo. Às vezes ele me olha. Eu olho de volta. Ele segue vagando pelo pátio. Um pouco corre, um pouco caminha. Merendeiras arrumando o lanche. Alguém diz que ele já pode comer. Bolacha e leite com chocolate. João pega bolachas. Alguém lhe alcança o copo com leite. Ele senta em um canto da mesa. Come. As crianças começam a chegar para lanchar. João já terminou. Passa por mim. Olho para ele, que me olha e desvia o olhar. Já são três e quarenta e cinco da tarde. Nesse momento, enfim sou chamada. João permanece no mesmo local. Depois, me pergunto: será que ele ficou por ali até às cinco e meia da tarde? ${ }^{1}$

Quando falamos em acessibilidade devemos sempre frisar que ela vai além do aspecto arquitetônico, ainda que esse seja o mais comum ou o mais lembrado. Ela é também metodológica, atitudinal e comunicacional. Muitas vezes, para não dizer na maioria delas, a forma como a pessoa com deficiência é tratada evidencia o preconceito e incapacita muito mais que a falta de uma rampa, por exemplo. A ausência da rampa denuncia um erro de construção ou até mesmo uma negligência, mas pode ser construída havendo recursos financeiros. Mas, uma atitude hostil, impregnada de preconceito, ou uma falsa cordialidade gerada pelo sentimento de pena, fere muito mais, porque é a constatação de que sim, eu sou diferente ${ }^{2}$. Pior, minha diferença não se encaixa nesse mundo, não se encaixa nessas pessoas. Eu sou diminuída, exposta, viro motivo de olhares curiosos. E, no fim, sou levada a sentir gratidão por ter sido bem tratada, porque nesse jogo de poder (MANTOAN, 2006), aquele que exerce a superioridade tem todo o controle.

O presente trabalho é parte das ações do Projeto Acessibilidade no ambiente escolar: aspectos arquitetônicos, metodológicos e atitudinais ${ }^{3}$, que teve como objetivo observar questões relativas à acessibilidade, verificando aspectos arquitetônicos, metodológicos e atitudinais em ambientes de ensino-aprendizagem, e para isso visitou 20 escolas da rede pública estadual e municipal de Santa Maria/RS no ano de 2018. Em um primeiro momento, foi feito um levantamento bibliográfico para aumentar nosso domínio 
sobre o tema e reconhecer as pesquisas realizadas nesta área. Após estudar o material, e como complemento à pesquisa bibliográfica, iniciamos a pesquisa documental, mapeando as escolas da cidade e elaborando um checklist com os aspectos arquitetônicos para verificação. Quanto aos aspectos relacionados à metodologia e atitude dos profissionais da educação, foram montadas entrevistas semiestruturadas que foram feitas com uma profissional da direção e com a educadora especial da escola, separadamente. Após esse trabalho de campo, os dados obtidos nos checklists serão analisados. Já as entrevistas estão sendo transcritas e analisadas segundo Bardin (1970).

O deslocamento até as escolas foi feito de transporte público, justamente para verificar a acessibilidade do trajeto, e, também, do próprio ônibus. O checklist ${ }^{4}$ foi adaptado do trabalho de Campos (2015), consistindo, principalmente, em aspectos arquitetônicos da escola que deveriam ser verificados, como, por exemplo, a existência de rampas, banheiros adaptados, livros acessíveis e acesso aos ambientes da escola. Após essa análise, eram realizadas as entrevistas, sendo seis perguntas para a diretora e sete para a educadora especial. Como as entrevistas tinham o caráter de ser semiestruturadas, perguntas além das estabelecidas foram feitas de acordo com as características particulares de cada escola. No momento da entrevista era explicado que pretendia-se gravar a conversa, mas os dados seriam utilizados sem identificação da pessoa. Caso ela concordasse, a mesma deveria indicar verbalmente seu aceite quando do início da entrevista. Além disso, o entrevistado era informado que os dados serviriam para a pesquisa acadêmica, podendo ser divulgados em eventos acadêmicos e periódicos científicos, sempre com atenção aos princípios éticos da pesquisa acadêmica.

Além da observação dos espaços, no sentido de mapear as condições atuais desses ambientes no que diz respeito à acessibilidade, o projeto tem como objetivo também desenvolver workshops com profissionais das escolas, compartilhando material teórico sobre a temática, bem como experimentações com práticas cênicas através de exercícios e jogos, capacitando os profissionais em abordagens cênicas acessíveis. Nesse primeiro ano foi possível realizar a atividade em apenas uma escola, mas para o próximo ano desejamos ampliar essa ação.

No presente artigo, a partir das ações desenvolvidas pelas integrantes do projeto durante o ano de 2018, iremos abordar algumas problematizações e desafios que a 
inclusão escolar vem enfrentando nas escolas da rede pública da cidade de Santa Maria (RS).

\section{O ESTUDANTE COM DEFICIÊNCIA E O CONTEXTO ESCOLAR}

De modo geral, a partir da vivência das autoras em contextos de ensino formal na educação básica, é possível observar que alunos com algum tipo de deficiência ${ }^{5}$, como Transtorno do espectro Autista, Transtorno do déficit de atenção e Distúrbios de Aprendizagem, fiquem longos períodos fora da sala de aula acompanhados de um monitor. O Poder Público tem a incumbência de ofertar, proporcionar a formação e disponibilizar um profissional de apoio escolar (monitor) que vai exercer atividades de alimentação, higiene e locomoção do estudante com deficiência, assim como atuar em todas as atividades escolares nas quais seu suporte se fizer necessário (BRASIL, 2015). Entretanto, esse profissional, que não recebe nenhuma formação adequada, parece uma espécie de pai/mãe, que fica atrás do aluno, falando com voz infantilizada, cuidando dos seus passos. Enquanto o monitor fica pelos corredores, conversando com um e com outro, o aluno fica sem rumo pelo pátio, conforme nos informa o relato que abre este artigo. É necessário que nos questionemos: seria essa a inclusão? Onde está o contato com os professores? E com os colegas? E a formação do cidadão? Qual o espaço para o cumprimento das regras e normas que todo aluno deve seguir na escola? Por que só alguns estão livres dessa obrigação? Por não "parar quieto" em sala o aluno fica vagando pelo pátio, sem rumo, sem saber o que fazer, onde gastar a energia da infância.

Essa tal "inclusão" em alguns momentos nos parece uma "miragem” construída pelo poder público, levando a maioria das escolas e da sociedade a acreditar, ou melhor, fingir acreditar, que está diante de algo efetivo, concreto. A adesão a essa "miragem" parece se sustentar pois, assim, não precisamos nos preocupar com esse ponto, não precisamos ver a incapacidade que é incluir nesses moldes. Fechamos os olhos, porque a verdade dói, nos faz olhar para as nossas incapacidades enquanto sociedade. Dessa forma, é muito mais fácil e menos incômodo acreditar que a inclusão está de fato ocorrendo nas escolas. Na minha opinião, grande parte do sistema educacional parece estar defasado e falido, e enquanto não revermos todo o funcionamento da escola e da educação, continuaremos iludidos e iludindo sobre inclusão. 
Parece que seria muito mais justo com os alunos, com os pais e com os professores se admitíssemos que essa acessibilidade total, para todos e em todos os momentos, essa ideia que nos venderam e nós compramos, não tem como ser colocada em prática. Como apresentado pela professora Márcia Lazzarin, não deveríamos ter a pretensão de incluir de modo total, mas pensar em experiências de inclusão, em micro experiências diárias ${ }^{6}$. Só assim estaremos sendo honestos com todos aqueles que estão sendo afetados nesse processo: alunos, pais, professores.

Como futura professora, será que a minha formação está me preparando para lidar com toda essa diversidade de corpos e modos de ser? Posso dizer que não! Como exemplo, cito minha formação enquanto licenciada em Ciências Biológicas. Durante minha graduação, a única disciplina voltada para essa temática foi LIBRAS I no quinto semestre, que é uma obrigatoriedade para todas as licenciaturas (BRASIL, 2005). No mais, tive o que julgo uma abordagem superficial do tema na disciplina de Didática I junto com outros temas ditos transversais. Temas esses que devem ser abordados segundo o Conselho Nacional de Educação:

\begin{abstract}
$\S 2^{\circ}$ Os cursos de formação deverão garantir nos currículos conteúdos específicos da respectiva área de conhecimento ou interdisciplinares, seus fundamentos e metodologias, bem como conteúdos relacionados aos fundamentos da educação, formação na área de políticas públicas e gestão da educação, seus fundamentos e metodologias, direitos humanos, diversidades étnico-racial, de gênero, sexual, religiosa, de faixa geracional, Língua Brasileira de Sinais (Libras), educação especial e direitos educacionais de adolescentes e jovens em cumprimento de medidas socioeducativas (BRASIL, 2015).
\end{abstract}

Sendo assim, nota-se que a educação especial fica diluída no meio de vários outros conteúdos, dificultando seu aprofundamento. E, se for analisar minha experiência, eu e praticamente todos os meus colegas contávamos com alunos com deficiência em sala de aula durante o estágio. Assim, ao refletir sobre o assunto, sigo me questionando: o que os cursos de licenciatura estão fazendo em relação a essa realidade? Segundo a legislação brasileira, todos os cursos de licenciatura têm a obrigatoriedade de incluir em sua grade 
curricular uma disciplina de LIBRAS (BRASIL, 2005), porém essa é a única disciplina voltada para a educação especial ${ }^{7}$ que os cursos são obrigados a oferecer.

Dessa forma, se os futuros professores seguem deixando a universidade sem uma formação adequada, é provável que os mesmos não saibam o que fazer, terminando por deixar o aluno num cantinho da sala, pintando, ou vagando pela escola, como vem ocorrendo em muitos $\operatorname{casos}^{8}$. E isso não parece ser inclusão! Acredito que a universidade e os cursos de licenciatura devem rever seus currículos para realmente encarar de frente esse tema, pois, de acordo com a legislação (BRASIL, 2015), desde 2015, os alunos com deficiência devem estar matriculados nas salas de aula comuns do ensino regular e no Atendimento Educacional Especializado (AEE). Além disso, a Política de Educação Especial vigente indica que os sistemas de ensino são responsáveis pelo "acesso aos espaços, aos recursos pedagógicos e à comunicação que favoreçam a promoção da aprendizagem e a valorização das diferenças, de forma a atender às necessidades educacionais de todos os estudantes" (BRASIL, 2008). Então os alunos vão estar na escola, mas os professores não estão sendo preparados para esse cenário.

No contexto das escolas verificadas no município de Santa Maria, o que percebese é que quando se fala em acessibilidade no ambiente escolar geralmente esse tema é compreendido apenas no quesito arquitetônico, com a construção de rampas e adaptações físicas na escola, quando na verdade a acessibilidade compreende uma gama de aspectos, como o metodológico, o comunicacional e o atitudinal, entre outros (VENDRAMIN, 2013, p. 02). Além disso, a qualidade dessas construções em muitos casos não atende às normas de engenharia (ASSOCIAÇÃO BRASILEIRA DE NORMAS TÉCNICAS, 2015), com rampas muito íngremes ou banheiros muito pequenos. Um fato que chama a atenção é que por mais que o maior investimento seja em adequações estruturais, o número de alunos com deficiência física nas escolas é extremamente pequeno se comparado com outros tipos de deficiências, como a intelectual, síndromes diversas e Transtorno do espectro autista.

Sendo assim, parece que o que as escolas mais precisam são metodologias diversificadas e formação dos professores, porém dentre os principais problemas relatados estão as dificuldades, e muitas vezes a resistência, dos professores trabalharem com os alunos com deficiências, assim como a quase inexistência de formação para os professores, tanto uma formação continuada, disponibilizada pelo Poder Público e pela 
própria escola, quanto aquela promovida durante a graduação. Algo que dificulta também essa formação é o calendário escolar ser muito justo, com pouco espaço para esses espaços de aprendizagem. Esse foi um dos motivos que impossibilitaram a realização total dos workshops promovidos pelas autoras.

Se os professores não possuem uma formação adequada, que contemple uma compreensão de como trabalhar com alunos com deficiências, assim como com problemas de aprendizagem, a inclusão escolar fica extremamente prejudicada (MASINI, 2004, p. 31). Em muitos casos, é necessário que o professor faça adaptações no conteúdo para possibilitar o melhor entendimento do aluno, e para tal, além de uma formação que introduza essas possibilidades e dê repertório, é imprescindível que ele tenha tempo disponível. Entretanto, no cenário atual brasileiro, com professores desvalorizados, com baixos salários - em alguns casos recebendo salários parcelados, como no Estado do RS -, com excesso de horas/aula e pressionados tanto pelo Estado - com Projetos como a Escola sem Partido e com mudanças no currículo do Ensino Médio sem o devido diálogo - quanto pelos pais, o tempo e a disponibilidade para que essas adaptações ocorram é praticamente impossível de acontecer.

Durante a realização do workshop ficou claro como os professores querem dialogar, contar sobre, compartilhar suas experiências, inclusive as boas experiências, eles só precisam de espaço e de quem os ouça. Os educadores nas instituições de ensino superior e intelectuais muito falam sobre a escola e o papel do professor, mas muitas vezes não vão à escola de fato, para se aproximar de como ela funciona na prática, ficando apenas no plano das ideias. Dessa forma, ocorre um distanciamento entre os professores, que estão vivenciando a escola no dia-a-dia, e as pessoas dentro da Academia, que são aquelas que majoritariamente escrevem sobre a escola. Se os professores não são ouvidos, não sabemos quais são os seus problemas e desafios, e assim não conseguimos auxiliálos.

Assim, pensamos que o workshop proposto funciona como um espaço de diálogo, de aproximação sensível na qual as práticas artísticas - em especial, nesse caso, as artes cênicas - são mediadoras para o entendimento e valorização do outro em sua singularidade, destacando que os repertórios e saberes podem ser atualizados dia a dia por meios dos encontros que a escola possibilita ${ }^{9}$. Acreditamos que o diálogo é a chave para solucionar muitos problemas enfrentados na escola. Como exemplo, podemos citar que 
no dia do workshop uma professora relatou sua preocupação com a comodidade de um aluno que era obeso e usava a mesma cadeira que os outros. Ela achava que ele se sentia desconfortável, mas não se sentia à vontade para trocar a cadeira dele por uma maior por pensar que o estudante poderia não gostar ou ser motivo de deboche por parte dos colegas. A professora perguntava o que nós achávamos que ela poderia fazer. A nossa resposta foi com outra pergunta: a senhora já perguntou se está ruim assim? E para nossa surpresa, essa pergunta nunca havia sido feita. Fazia meses que ela estava aflita com aquela situação, mas até o momento não tinha feito o mais simples que era conversar com o aluno e saber qual o seu sentimento diante daquele fato. Esse exemplo esclarece a importância do diálogo e como devemos exercitá-lo no dia-a-dia.

Também foi verificada uma significativa diferença entre as escolas municipais e estaduais, principalmente no que se refere às verbas disponibilizadas pelo Poder Público, organização estrutural, presença de monitores e equipamentos na Sala de Recursos Multifuncionais, com melhor assistência aos estudantes nas escolas municipais. Isso pode ser explicado pelo número menor de turmas atendidas - as escolas municipais atendem apenas o ensino básico, enquanto as estaduais abrangem o ensino básico e médio -, facilitando assim o manejo dos recursos tanto financeiros quanto humanos. Entretanto, não podemos esquecer que os diversos problemas financeiros que o Estado do Rio Grande do Sul vem passando afetam também as escolas, como a falta de recursos enviados às escolas e a precarização do ensino, sem contar no próprio parcelamento dos salários dos professores que de forma indireta influencia a qualidade do ensino/aprendizagem, com profissionais por vezes desmotivados. Essa situação dos professores informa sobre o tamanho descaso do Estado com relação à educação, e o quanto esse descaso afeta o trabalho feito pelos profissionais da educação.

A maioria das diretoras ${ }^{10}$ das escolas demonstraram-se receptivas a participar da pesquisa, sendo extremamente solícitas e demonstrando um real interesse em mostrar a escola e participar da entrevista solicitada pela autora, entretanto em algumas escolas esse comportamento não foi verificado, com diretoras pouco disponíveis e/ou constrangidas em admitir a falta de acessibilidade que sua escola apresentava. Em duas ocasiões, inclusive, as diretoras solicitaram previamente as perguntas que seriam realizadas na entrevista. 
Um outro fato verificado foi o entendimento dos professores e das diretoras das escolas de que os alunos com deficiência são responsabilidade da educadora especial, e não da escola como um todo. Sendo assim, os professores não se sentem responsáveis pelo aprendizado do aluno, delegando essa função para a educadora especial, ainda que a mesma não tenha a função de trabalhar o conteúdo isoladamente com o estudante, visto que o Atendimento Educacional Especializado (AEE) não é um reforço escolar, embora muitas vezes seja assim confundido.

O AEE é hoje oferecido preferencialmente em Salas de Recursos Multifuncionais (SRM), por um profissional especializado, a educadora especial, geralmente no contraturno da matrícula na sala de aula comum. Tem por função, no caso específico da educação especial ${ }^{11}$, complementar a formação dos estudantes com deficiência ou transtornos globais do desenvolvimento ao ensino regular (BRASIL, 2011) por meio da "disponibilização de serviços, recursos de acessibilidade e estratégias que eliminem as barreiras para sua plena participação na sociedade e desenvolvimento de sua aprendizagem" (BRASIL, 2009). Ainda segundo a legislação, o Poder Público assegurará a dupla matrícula do estudante com deficiência.

Além disso, um outro fator problemático, é a falta de um trabalho colaborativo entre os professores das salas de aula regulares e a educadora especial que atende no AEE. E isso acontece, muitas vezes, devido à precariedade das condições de trabalho desses profissionais (BATISTA et al., 2018), além do desconhecimento do professor da sala regular sobre a atuação do AEE como atendimento pedagógico.

\section{A FORMAÇÃo DO FUTURO PROFESSOR - PROBLEMATIZAÇÕES E DESAFIOS}

De modo a modificar essa conjuntura, parece necessário que passemos a nos questionar o que seria uma formação ideal para o professor. Ao destacar uma formação ideal, não temos a pretensão de sugerir que ela vá suprir toda e qualquer possível dúvida do professor - até porque isso seria impossível e também indesejável, já que esses momentos de indecisão e conflito são necessários para gerar o novo e o criativo pensamos mais em uma perspectiva que destaque a alteridade. Uma formação que mobilize o aluno de graduação a encontrar estratégias para além do habitual, da 
comodidade, sem perder de vista os sujeitos que participam dos processos de ensinoaprendizagem.

Inclusão, do verbo incluir, no seu sentido etimológico, significa "conter em, compreender, fazer parte de, ou participar de" (MASINI, 2004, s/p). Dessa forma, falar de inclusão escolar deveria significar que todo e qualquer aluno tem as mesmas condições que os demais para participar do que o ambiente escolar proporciona. Porém, diante da nossa realidade, penso que deveríamos rever o conceito de inclusão e o que queremos quando usamos essa palavra. Porque se inclusão é simplesmente tirar a pessoa com deficiência de dentro de casa e colocar ela dentro da escola, bom, podemos dizer que estamos incluindo. Entretanto, se assim for, devemos repensar qual é o papel da escola. Ela é um local para formar cidadãos capazes de viver em sociedade, ou um local que funciona como um depósito para dar um descanso aos pais ou para ter onde deixar enquanto eles estão trabalhando, ou ainda, para formar mão de obra barata, direcionando os estudantes para subempregos? ${ }^{12}$

Se, contudo, entendermos a inclusão como a tentativa de proporcionar oportunidades justas para todas as pessoas, e propiciar um ambiente acessível, estamos bem longe. Skliar \& Souza (2009, s/p.) questionando o papel da escola e em relação ao projeto inclusivista do governo se perguntam "quais são os argumentos que fundamentam as propostas de inclusão e, por outro lado, qual é a política de significados e as representações que se produzem e reproduzem nessa proposta". Ainda, é necessário destacar que o questionamento sobre as políticas de inclusão não significa a negação dos avanços e das melhorias, ainda que pequenas, do ensino das pessoas com deficiência.

\footnotetext{
A crítica ao discurso dominante de inclusão nada tem que ver com uma cega afinidade ou com uma defesa desnecessária das escolas e das pedagogias especiais. Não é essa a interpretação que se deve fazer. A aparente oposição entre escola especial e escola comum somente remete a um aspecto, que é o da institucionalização ou, dito de outro modo, o da localização -melhor ou pior- dos deficientes nos sistemas de ensino oficiais e não oficiais.

Não se vislumbra, entretanto, uma olhada crítica para ambos sistemas de escolarização. $\mathrm{O}$ questionamento sobre para que serve a escola
} 
pode ser, assim, silenciado. (SKLIAR; SOUZA, 2009, s/p.)

Esses questionamentos são motes para a necessidade de rever o conceito e esclarecer o que queremos com ele. Dessa forma, estaremos sendo justos com a sociedade de um modo geral.

Em grande parte das escolas visitadas, o conceito de inclusão era associado somente a não rejeição da matrícula - uma vez que a rejeição da matrícula configura prática ilegal (BRASIL, 2015) - ou à existência de alunos com deficiências nas suas dependências. Dessa forma, eram utilizadas frases como "a nossa escola possui alunos incluídos" ou "os alunos da inclusão", porém em muitos casos esses alunos só estavam dentro da escola, mas não participavam das aulas em sala de aula, nem das atividades escolares. Esse exemplo mostra como o conceito de inclusão não é bem compreendido nem pelos profissionais que trabalham nesse contexto escolar, elucidando a importância de rever o conceito e deixar ele claro para todos.

Neste ponto, adentramos em outra questão primordial, que seja: a compreensão do espaço escolar na contemporaneidade. Se observarmos com atenção, qual aluno hoje em dia gosta de ficar em sala de aula? Ainda que não seja fácil reconhecer, a escola, mais especificamente a sala de aula, não é um ambiente atrativo na grande maioria das vezes. Se a oportunidade de sair da sala fosse dada para todos os estudantes, como é dada para os alunos com deficiências, qual deles iria recusar? Por que ela é prática comum para alguns e fora das regras para os outros? Atitudes como essa só reforçam o preconceito e a aversão sofrida pelos alunos com deficiência, já que afastam os colegas e ampliam a sensação de diferença e estranheza por parte do estudante com deficiência. Sua formação, assim, é prejudicada por não conviver com os colegas, não participar das atividades realizadas em sala com os demais e não acompanhar o conteúdo dado. Sendo assim, para a criação da inclusão é preciso uma redefinição do conceito de educação (MANTOAN, 2006).

Entendemos que a escola tem um papel importantíssimo no trabalho com as diferenças, ainda que em um primeiro momento usar a palavra "diferença" nos afaste, ao mesmo tempo, precisamos reconhecer as diferenças que nos formam. Diferença pelo viés da alteridade, daquilo que forma o sujeito sem hierarquizar em categorias, principalmente 
no momento no qual vivemos, com a ascensão do conservadorismo em diversos contextos. Segundo Mantoan (2006, p. 192), "as ações educativas inclusivas têm como eixos o convívio com as diferenças, a aprendizagem como experiência relacional, participativa, que produz sentido para o aluno, [...] construída no coletivo das salas de aula”. Assim, acreditamos que a alteridade deve ser entendida como um princípio ético no processo formativo.

As pesquisadoras Berselli \& Isaacsson (2018, p. 56) apontam que a colaboração, dentro do processo criativo, pode ser formativa para todos os envolvidos, tendo eles deficiência ou não, "sem que se anulem os repertórios particulares, mas encontrando na diferença e distinção benefícios e desafios, sem privilegiar um conceito categorizante que toma o outro como uma determinada representação". Sendo assim, a escola deve ser compreendida como um espaço no qual as relações sejam promovidas, instigadas, porém, em muitos casos, não é assim que vem acontecendo. Principalmente pelo fato de a escola ser um ambiente extremamente normatizador, um local onde há um padrão - de aluno ideal e de ensino - que deve ser seguido. E é justamente essa padronização que impede que as relações e a colaboração sejam exercitadas, pois nossas escolas são construídas segundo o modelo das linhas de montagem (ALVES, 2001).

Um bom exemplo a ser citado, é o que ocorre na Escola da Ponte ${ }^{13}$, fundada em 1976 em Portugal, que assenta seus valores na solidariedade, autonomia e responsabilidade (GUARDA; OLIVEIRA, 2007). Nesse modelo, a aprendizagem acontece respeitando o tempo e o desejo dos alunos, seguindo as experiências que cada um está vivenciando. E, como cada aluno aprende segundo o seu tempo, com aqueles que têm alguma deficiência isso não é diferente. Dessa forma, a educação "de qualquer pessoa, deficiente ou não, precisa ter metas e objetivos iguais” (PADILHA, 2006, p. 46), ou seja, o papel de uma escola realmente inclusiva é educar para a vida, formando cidadãos conscientes e críticos para sua realidade. Assim, defendemos uma escola que na sua estrutura de ensino contemple os sujeitos nas suas totalidades: respeitando seus tempos e seus modos de relação com o mundo.

Nesse sentido, atividades formativas desenvolvidas com os professores e profissionais que já atuam nos ambientes de ensino-aprendizagem, fornecendo ferramentas e favorecendo o conhecimento de práticas que promovam a interação entre estudantes com e sem deficiência parecem fundamentais para que se amplie o acesso 
efetivo das pessoas com deficiência aos sistemas de ensino. O desconhecimento das questões relativas à deficiência é fator que alimenta o preconceito, tornando o espaço da escola, muitas vezes, local que reforça estereótipos da deficiência. Além dos dados levantados, que auxiliarão na continuidade das atividades do projeto, buscando uma resposta mais efetiva aos problemas encontrados, o projeto aqui apresentado revelou a importância das atividades formativas com os professores, sendo que o contato sensível, as partilhas e trocas de experiência vivenciadas com outros, colaboram para a erosão do preconceito, e revelam que só é possível conhecer o outro ao me aproximar dele. Isso serve não apenas para a aproximação entre professor e estudante, estudante e estudante, mas, também, entre universidade e escola.

\section{AGRADECIMENTOS}

Agradecemos a Pró Reitoria de Extensão e o Centro de Artes e Letras da UFSM pelo suporte financeiro. Especialmente, agradecemos as escolas de Santa Maria, a Secretaria Municipal de Educação e a $8^{\text {a }}$ Coordenadoria Regional de Educação que nos acolheram para a realização do projeto.

\section{NOTAS}

1 Cena presenciada pela primeira autora do artigo, em uma escola estadual da cidade de Santa Maria/RS. Na sequência do texto a cena será retomada.

2 Em algumas partes do texto, opta-se pelo uso da primeira pessoa do singular, destacando o lugar de fala da primeira autora, pessoa com deficiência e futura professora.

3 O Projeto, vinculado ao Centro de Artes e Letras da Universidade Federal de Santa Maria (CAL/UFSM), é parte das ações do Programa de Extensão Práticas cênicas, escola e acessibilidade, do Grupo de Pesquisa Teatro Flexível: práticas cênicas e acessibilidade (CNPq/UFSM). O Programa de Extensão conta com recursos FIEX/CAL.

4 Posteriormente, o checklist será disponibilizado no site do projeto: www.teatroflexivel.com.br 
5 Quando usamos o termo deficiência, reconhecemos que "a deficiência é um conceito em evolução e que a deficiência resulta da interação entre pessoas com deficiência e as barreiras devidas às atitudes e ao ambiente que impedem a plena e efetiva participação dessas pessoas na sociedade em igualdade de oportunidades com as demais pessoas" (BRASIL, 2009).

6 Informação advinda das anotações da primeira autora, a partir de palestra apresentada pela Profa. Dra. Márcia Lazzarin no I Simpósio Pensamento Acessível - Cena Aberta, em agosto de 2018 na Universidade Federal de Santa Maria (Santa Maria/RS).

7 As autoras utilizam o termo educação especial, a partir de seu emprego nos documentos oficiais sobre o ensino básico, como a Lei de Diretrizes e Bases da Educação Nacional (1996). Em relação às diretrizes específicas de Santa Maria, usou-se como referência a Resolução no 31, de 12 de dezembro de 2011, do Conselho Municipal de Educação de Santa Maria (CMESM), documento que apresenta as Diretrizes Curriculares para a Educação Especial no Sistema Municipal de Ensino de Santa Maria - RS.

8 À guisa de exemplo, destacamos o relato apresentado no início deste texto, que apresenta um fato vivenciado pela primeira autora.

9 Além de palestra e roda de conversa, as professoras foram convidadas a desenvolver atividades cênicas, nas quais colocavam seus corpos em movimento e em contato com as demais. As atividades escolhidas privilegiavam o tempo de cada participante e suas possibilidades, sem haver um modelo único a ser seguido por todas. Unindo o lúdico e o criativo, as professoras foram apresentadas a atividades simples que podem ser incorporadas ao seus fazeres, buscando promover a interação e o contato entre os estudantes.

10 As autoras escolheram utilizar o substantivo no feminino já que a grande maioria das entrevistadas foram mulheres.

11 O Atendimento Educacional Especializado, além de atender os alunos com deficiências e transtornos globais do desenvolvimento, também atende os alunos com altas habilidades ou superdotação.

12 Perguntas que possibilitariam e exigiriam, certamente, amplos debates que o presente texto não irá abarcar. Fica, contudo, aqui, um início de discussão. Conforme Venco e Carneiro (2018, p. 14): 'Consoante com Patto (2010) sobre 
as metas empreendidas pela educação brasileira alinhadas com organismos internacionais, é importante destacar as intencionalidades ocultadas por um discurso dissimulado em prol da educação de qualidade. Para a autora, os objetivos de tal opção política visam: a) lograr alguns objetivos, quais sejam: redução de custos com a educação e ajustá-la à economia que rege a ordem mundial; b) ampliar as estatísticas sobre a escolaridade da população, sem considerar, contudo, a qualidade da educação; c) conferir aos "excluídos a ilusão que estão sendo incluídos na escola e, pela obtenção do diploma, no universo do trabalho'."

13 No Brasil existe o Projeto Âncora, na cidade de Cotia (SP), que possui um modelo organizacional de gestão democrática e uma reorganização das estruturas educativas tradicionais, assim como a Escola da Ponte.

\section{REFERÊNCIAS}

ASSOCIAÇÃO BRASILEIRA DE NORMAS TÉCNICAS. NBR 9050: Acessibilidade a edificações, mobiliário, espaços e equipamentos urbanos. Rio de Janeiro, p. 162. 2015.

ALVES, R. Escola com Que Sempre Sonhei Sem Imaginar Que pudesse existir. Campinas: Papirus Editora, 2001.

BARDIN, L. Análise de conteúdo. Lisboa: Edições 70, 1977.

BATISTA, R. D., AMARAL, M. H. do; MONTEIRO, M. I. B. Quem ensina braille para alunos cegos? A formação de professores em questão. Horizontes, v. 36, n. 01, p. 36-49, jan./abr. 2018. Disponível em https://revistahorizontes.usf.edu.br/horizontes/article/view/676. Acesso em 10 dez. 2018.

BERSELLI, M.; ISAACSSON, M. Práticas cênicas acessíveis e a interação entre artistas com e sem deficiência: um breve olhar sobre o trabalho dos encenadores Bob Wilson e Pippo Delbono. Pitágoras 500, 8(2), 2018. Disponível em https://periodicos.sbu.unicamp.br/ojs/index.php/pit500/article/view/8653873. Acesso em $01 \mathrm{dez} .2018$. 
BRASIL. Decreto $\mathbf{n}^{0}$ 5.626, de 22 de dezembro de 2005. Regulamenta a Lei ${ }^{\circ}$ 10.436, de 24 de abril de 2002, que dispõe sobre a Língua Brasileira de Sinais - Libras, e o art. 18 da Lei ${ }^{\circ} 10.098$, de 19 de dezembro de 2000.

Decreto $n^{0}$ 6.949, de 25 de agosto de 2009. Promulga a Convenção Internacional sobre os Direitos das Pessoas com Deficiência e seu Protocolo Facultativo, assinados em Nova York, em 30 de março de 2007. Brasília, DF, 25 ago. 2009.

Decreto $\mathbf{n}^{0}$ 7.611, de 17 de novembro de 2011. Dispõe sobre a educação especial, o atendimento educacional especializado e dá outras providências.

Ministério de Educação e Cultura. Lei n. 9.394 de 20 de dezembro de 1996. Estabelece as diretrizes e bases da educação nacional. Diário Oficial da União, Brasília, 1996.

Lei $\mathrm{n}^{\circ} 13.146$ de 06 de Julho de 2015. "Lei Brasileira de Inclusão da Pessoa com Deficiência" (Estatuto da Pessoa com Deficiência). Subchefia para Assuntos Jurídicos [da] Presidência da República. Brasília, DF, 06 jul. 2015.

MEC/SECADI. Política nacional de educação especial na perspectiva da educação inclusiva. 2008.

Ministério da Educação. Conselho Nacional de Educação. Resolução no 2, de 1 de julho de 2015. Define as Diretrizes Curriculares Nacionais para a formação inicial em nível superior (cursos de licenciatura, cursos de formação pedagógica para graduados e cursos de segunda licenciatura) e para a formação continuada. 2015.

CAMPOS, R. A. de. Acessibilidade espacial na arquitetura escolar: avaliação pós-ocupação do Projeto Padrão 12 salas FNDE. 2015. 309f. Dissertação (Mestrado em Arquitetura e Urbanismo) - Universidade Federal de Santa Catarina, Florianópolis, 2015.

GUARDA, N. S. de.; OLIVEIRA, A. A. S. de. Escola da Ponte: um exemplo de escola inclusiva. In: IV Congresso Brasileiro Multidisciplinar de Educação Especial, 2007, Londrina/PR. Anais. Londrina/PR: Universidade Estadual de Londrina, 2007.

MANTOAN, M. T. E. O direito de ser, sendo diferente, na escola. In: RODRIGUES, D. (Org.). Inclusão e Educação: doze olhares sobre a educação inclusiva. São Paulo: Summus, p. 183-209, 2006. 
MASINI, E. A. F. S. Uma experiência de inclusão - providências, viabilização e resultados. Educar, Curitiba, n. 23, p. 29-43, 2004.

PADILHA, A. M. L. Práticas pedagógicas e a inserção sócio-cultural do deficiente: a complexidade da proposta. In: MANZINI, E. J. (Org.). Inclusão e Acessibilidade. Marília: Fundepe, p. 43-50, 2006.

SKLIAR, C., SOUZA, R. M. D. Considerações sobre as diferenças: caminhos para se (re) pensar a educação. Laboratório Interdisciplinar de Tecnologias EducacionaisLITE, Faculdade de Educação-FE, Universidade Estadual de Campinas-Unicamp, 2009.

VENDRAMIN, C. Diversas danças - diversos corpos: discursos e práticas da dança no singular e no plural. In: DO CORPO: Ciências e Artes, Caxias do Sul, v. 1, n. 3, p. 118 , 2013. Disponível

em http://www.ucs.br/etc/revistas/index.php/docorpo/article/view/2904. Acesso em 05 dez. 2018.

VENTO, S. B.; CARNEIRO, R. F. "Para quem vai trabalhar na feira... essa educação está boa demais": a política educacional na sustentação da divisão de classes. Horizontes, v. 36, n. 01, p. 07-15, jan./abr. 2018. Disponível em https://revistahorizontes.usf.edu.br/horizontes/article/view/660. Acesso em 04 fev. 2019.

Recebido em: 25 de julho de 2018. Aceito em: 31 de março de 2019. 